A Weibull Brittle Material Failure Model for the ABAQUS Computer Program

Joel Bennett

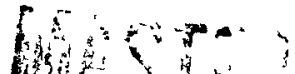




\section{DISCLAIMER}

This report was prepared as an account of work sponsored by an agency of the United States Government. Neither the United States Government nor any agency Thereof, nor any of their employees, makes any warranty, express or implied, or assumes any legal liability or responsibility for the accuracy, completeness, or usefulness of any information, apparatus, product, or process disclosed, or represents that its use would not infringe privately owned rights. Reference herein to any specific commercial product, process, or service by trade name, trademark, manufacturer, or otherwise does not necessarily constitute or imply its endorsement, recommendation, or favoring by the United States Government or any agency thereof. The views and opinions of authors expressed herein do not necessarily state or reflect those of the United States Government or any agency thereof. 


\section{DISCLAIMER}

Portions of this document may be illegible in electronic image products. Images are produced from the best available original document. 



\section{CONTENTS}

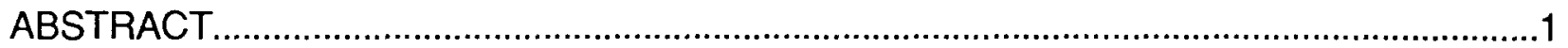

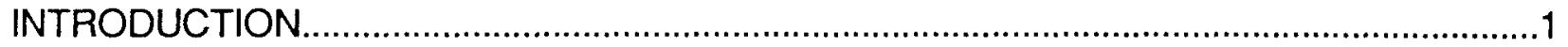

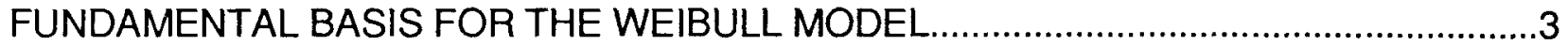

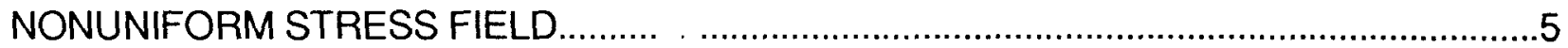

PRINCIPLE OF INDEPENDENT ACTION (PIA) AND MULTIAXIAL STRESS FIELDS....7

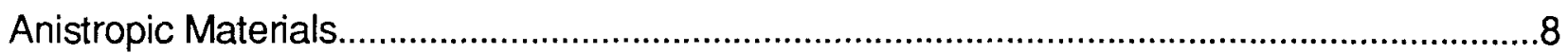

Finite Element Implementation...........................................................................10

A FURTHER DISCUSSION OF THE MEAN UNIT VOLUME STRENGTH..................12

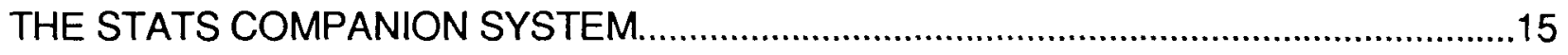

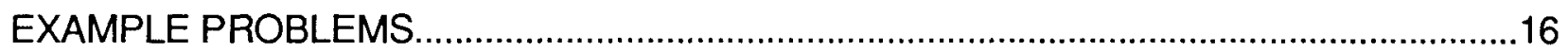

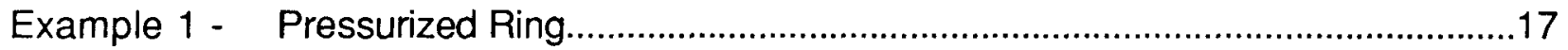

Example 2 - A Silicon Nitride Disc, Spin-Tested to Failure......................................19

Example 3 - A Graphite Ring Experiment Under External Mechanical Load and a Thermal Gradient................................................................................... 19

Example 4 - An MHTGR Fuel Block Under Normal Operation....................................23

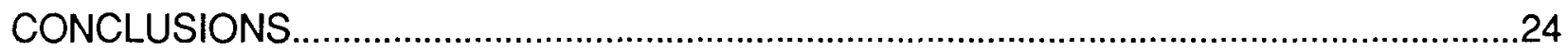

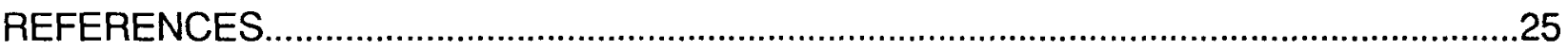

FIGURES

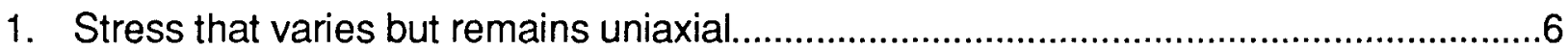

2. Principal stresses acting on a differential volume element dv.

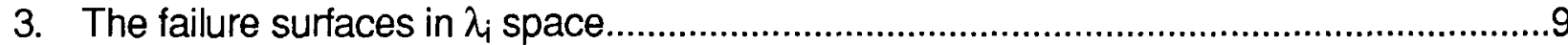

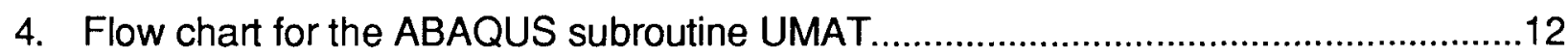

5. The MOR test specimen configuration corresponding to Eq. 16.........................14

6. The Weibull cumulative distribution function and properties $\bar{\sigma}_{\mathfrak{f}}$ and $m$, determined from Ref. 9, for the with-grain experiments on graphite tensile specimens. The curve is the Weibull fit, with the data points shown as squares.

7. A comparison of the ABAQUS POF model vs the exact solution for the $P O F$ of a thick ring under internal pressure. 
8. Various Weibull models compared with the experimental data from Ref. 7

9. Quarter-symmetry plane-stress mesh for example 3................................................

10. The POF prediction by ABAQUS for the loaded graphite ring, from Ref. 11, with the 4-point experimental data band and the mean shown for comparison

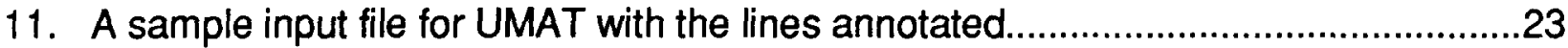

12. The finite element mesh for example problem 4. The fuel is a heat-generating source, and only the POF of the graphite is required

\section{TABLES}

I. THICK WALL CYLINDER ANALYSIS.

II. THE PARAMETERS USED FOR THE CALCULATIONS SHOWN IN FIG. 8

III. PARAMETERS USED IN CALCULATIONS FOR EXAMPLE 3.

IV. PARAMETERS USED FOR THE CALCULATIONS OF EXAMPLE 4. 


\title{
A WEIBULL BRITTLE MATERIAL FAILURE MODEL FOR THE ABAQUS COMPUTER PROGRAM
}

\author{
by \\ Joel Bennett
}

\begin{abstract}
A statistical failure theory for brittle materials that traces its origins to the Weibull distribution function is developed for use in the general purpose ABAQUS finite element computer program. One of the fundamental assumptions for this development is that Mode I microfractures perpendicular to the direction of the principal stress contribute independently to the fast fracture. The theory is implemented by a user subroutine for ABAQUS. Example problems illustrating the capability and accuracy of the model are given.
\end{abstract}

\section{INTRODUCTION}

Brittle materials (glasses, ceramics, graphites, and concrete) exhibit a scatter in their fracture strength. Current theory says that such a scatter is caused by the distribution of microscopic flaws intrinsic in the material. However, many other properties, such as corrosion resistance, low thermal conductivity, etc., of this class of materials have made them very attractive for use as a structural material. One of their chief attractions is high-temperature strength and, thus, their structural applications have focused on heat engines, turbine blades, and reactor cores. Their "brittle" characteristic (linear or near-linear stress-strain behavior to fracture) and their near-zero ductility, combined with the large scatter in fracture strength, have led to a probabilistic approach for a design philosophy when brittle materials are used.

Weibull ${ }^{1}$ first proposed that statistics be used in a probabilistic prediction method. He used a weakest link theory (WLT) and assumed a unique form for the cumulative distribution for uniaxial fracture data, which he determined by simple tension tests. Later he demonstrated that the distribution function he had assumed had wide applicability to many naturally occurring processes. ${ }^{2}$ 
A number of papers and reports that appeared in the literature in the 1970s and 1980s dealt with the Weibull approach to fast fracture. Generally, they took one of the following forms:

(1) papers that deal with reporting the influence of the assumed cumulative distribution function; 3

(2) papers that attempt to combine the statistical approach with Griffith-IrwinOrowan fracture mechanics;4-6

(3) papers and reports on experimental results and their correlation;7-10

(4) papers that describe the Weibull approach and its applications to various design problems; $8-11$

(5) and papers that discuss combining the statistical approach with finite element stress analysis codes and methods. ${ }^{12-14}$

Handbooks on brittle material design are represented by Refs. 15 and 16.

The principal point of agreement of all of these works is that the Weibull approach has good utility for the design of brittle material components. For the same reason, the approach provides an excellent tool for safety evaluation studies of graphite reactor core components such as those proposed for usage in the New Production Reactor (NPR) and, in particular, the modular high-temperature gas-cooled reactor (MHTGR) concept. This application is one of the primary motivations for the research reported here.

The work reported in Refs. 12-14 deals with postprocessing schemes for finite element computer codes. The approach taken in the work reported here is to include a Weibull probability of failure (POF) estimation in the finite element solution process. Indeed, in the conventional finite element displacement formulation, recovery of stresses is, in some sense, a "post-calculation." Because all information necessary to calculate the POF on an element-by-element basis is available at this point in the calculational flow, the most logical place to implement this computation seems to be at the point of stress recovery.

Since its introduction at the Los Alamos National Laboratory, the widely used ABAQUS 17 code has become a production code for many users who deal with stress analysis and heat transfer. One of the better features of the ABAQUS general purpose finite element code is the ability to add user-coded subroutines for describing new elements, materials, loads, constraints, etc. The author has used many of these features, usually with good results, ${ }^{18}$ and these features are improved with each new version of the code. This report will describe the implementation of a Weibull POF model for Version 4.8 of the code. 


\section{FUNDAMENTAL BASIS FOR THE WEIBULL MODEL}

Weibull 1 postulated that a uniformly stressed volume in a state of uniaxial tension $\sigma$ has a set of failure statistics described by the three-parameter equation,

$$
P_{f}=1-\exp \left\{-\left[\frac{\sigma-\sigma_{u}}{\sigma_{0}}\right]^{m}\right\}
$$

where

$\mathrm{P}_{\mathrm{f}}=$ probability of failure,

$\sigma_{u}=$ the "threshold" stress for which $P_{f}$ is finite, usually assumed zero,

$\sigma_{o}=$ one of the Weibull distribution fitting parameters for a set of data, and

$\mathrm{m}=$ a second Weibull distribution fitting parameter for the data set ( $\mathrm{m}$ is called the Weibull modulus).

This cumulative distribution function has the derivative, with respect to $\mathrm{s}$, given by

$$
F(\sigma)=\frac{m}{\sigma_{0}}\left(\frac{\sigma-\sigma_{u}}{\sigma_{0}}\right)^{m-1} \exp \left\{-\frac{\left(\sigma-\sigma_{u}\right)^{m}}{\sigma_{0}}\right\}
$$

Equation 2 is the frequency or probability distribution function for the cumulative distribution function in Eq. (1) for the data set. The mean failure stress $\bar{\sigma}_{f}$ will be given by

$$
\bar{\sigma}_{f}=\int_{0}^{\infty} \sigma F(\sigma) d \sigma .
$$

If the substitution that

$$
\left(\frac{\sigma-\sigma_{u}}{\sigma_{0}}\right)^{m}=x
$$

is made into the expression for this integral, then the mean failure stress can be written as

$$
\bar{\sigma}_{f}=\sigma_{\circ} \Gamma\left(\frac{1}{m}+1\right)+\sigma_{u}
$$

where the gamma function, which is defined as 


$$
\Gamma(n)=\int_{0}^{\infty} x^{n-1} e^{-x} d x
$$

has been used. ${ }^{19}$

One of the properties of the gamma function is that

$$
n !=\Gamma(n+1), \text { so that } \bar{\sigma}_{f}=\sigma_{o}\left(\frac{1}{m} !\right)+\sigma_{u}
$$

is a notation that is often seen. Note that the gamma function is a continuous function of $n$ if $n>-1$; it is, thus, sometimes called the generalized factorial function because $n$ is not required to be an integer.

The substitution of Eq. (3) into Eq. (1) and some algebra will show that

$$
P_{f}=1-\exp \left\{-\left[\left(\frac{1}{m} !\right)\left(\frac{\sigma-\sigma_{u}}{\overline{\sigma_{f}}-\sigma_{u}}\right)\right]^{m}\right\}
$$

We define the probability of survival of a uniformly stressed element as

$$
P_{s}=\exp \left\{-\left[\left(\frac{1}{m} !\right)\left(\frac{\sigma-\sigma_{u}}{\bar{\sigma}_{f}-\sigma_{u}}\right)^{m}\right\}\right.
$$

Then consider a uniformly stressed tensile specimen of volume $\mathrm{V}$. We let $\mathrm{V}$ be made of $\mathrm{N}$ unit volumes $\mathrm{v}$ so that $\mathrm{V}=\mathrm{Nv}$. For a uniaxial specimen, the probability of survival of any given unit volume $i$ is

$$
P_{s}^{i}=\exp \left\{-\left[\left(\frac{1}{m} !\right)\left(\frac{\sigma-\sigma_{u}}{\bar{\sigma}_{u v f}-\sigma_{u}}\right)\right]^{m}\right\}
$$

where $\bar{\sigma}_{\text {uvf }}$ is the mean unit volume failure stress. The survival probability of the uniformly stressed uniaxial specimen is the product of the survival probabilities of all the unit volumes, that is,

$$
P_{s}^{\text {total }}=P_{s}^{(1)} \times P_{s}^{(2)} \times P_{s}^{(3)} \times \ldots P_{s}^{(n)}
$$

Taking the natural logarithm of both sides of this expression, we have 


$$
\ln P_{s}^{\text {total }}=\ln P_{s}^{(1)}+\ln P_{s}^{(2)}+\ldots \ln P_{s}^{(n)}
$$

and substituting the expression for $P_{s}^{(i)}$, we have

$$
\ln P_{s}^{\text {total }}=\sum_{i=1}^{n}\left\{\left[\left(\frac{1}{m} !\right)\left(\frac{\sigma-\sigma_{u}}{\bar{\sigma}_{u v f}-\sigma_{u}}\right)\right]^{m}\right\}^{(i)}=-N\left\{\left[\left(\frac{1}{m} !\right)\left(\frac{\sigma-\sigma_{u}}{\bar{\sigma}_{u v f}-\bar{\sigma}_{u}}\right)\right]\right\}^{m} .
$$

There are various ways to handle the test data, but, from the test data, a Weibull curve fit is given by

$$
\ln P_{s}^{\text {total }}=-\left(\frac{\sigma-\sigma_{u}}{\bar{\sigma}_{f}-\sigma_{u}}\right)^{m}
$$

then equating the two expressions for $\ln \mathrm{Ps}^{\text {total }}$, will result in

$$
N\left\{\left[\left(\frac{1}{m} !\right)\left(\frac{\sigma-\sigma_{u}}{\bar{\sigma}_{u v f}-\sigma_{u}}\right)^{m}\right\}=\left(\frac{\sigma-\sigma_{u}}{\bar{\sigma}_{f}-\sigma_{u}}\right)^{m} .\right.
$$

By substituting,

$$
\begin{aligned}
& N=\frac{V}{V} \\
& \left\{\frac{V}{V}\right\}^{1 / m}\left(\frac{1}{\bar{\sigma}_{u v f}-\sigma_{u}}\right)\left(\frac{1}{m} !\right)=\frac{1}{\bar{\sigma}_{f}-\sigma_{u}} .
\end{aligned}
$$

So $\bar{\sigma}_{\text {uvf }}$ and $\bar{\sigma}_{\mathrm{f}}$ are related by

$$
\bar{\sigma}_{u v f}=\left(\frac{1}{m} !\right)\left(\frac{V}{v}\right)^{1 / m}\left(\bar{\sigma}_{f}-\sigma_{u}\right)+\sigma_{u}
$$

We again note $|v|=1$, but we keep the symbol for clarity and dimensional homogeneity. Equation (5) is the key equation for determining the mean unit volume strength from a tensile specimen data set.

\section{NONUNIFORM STRESS FIELD}

Consider a magnitude-varying but uniaxial stress field acting on a finite volume $\Delta v$ (Fig. 1). Associated with each point Dv, there is a $P \mathcal{S}^{\Delta V}$, so 


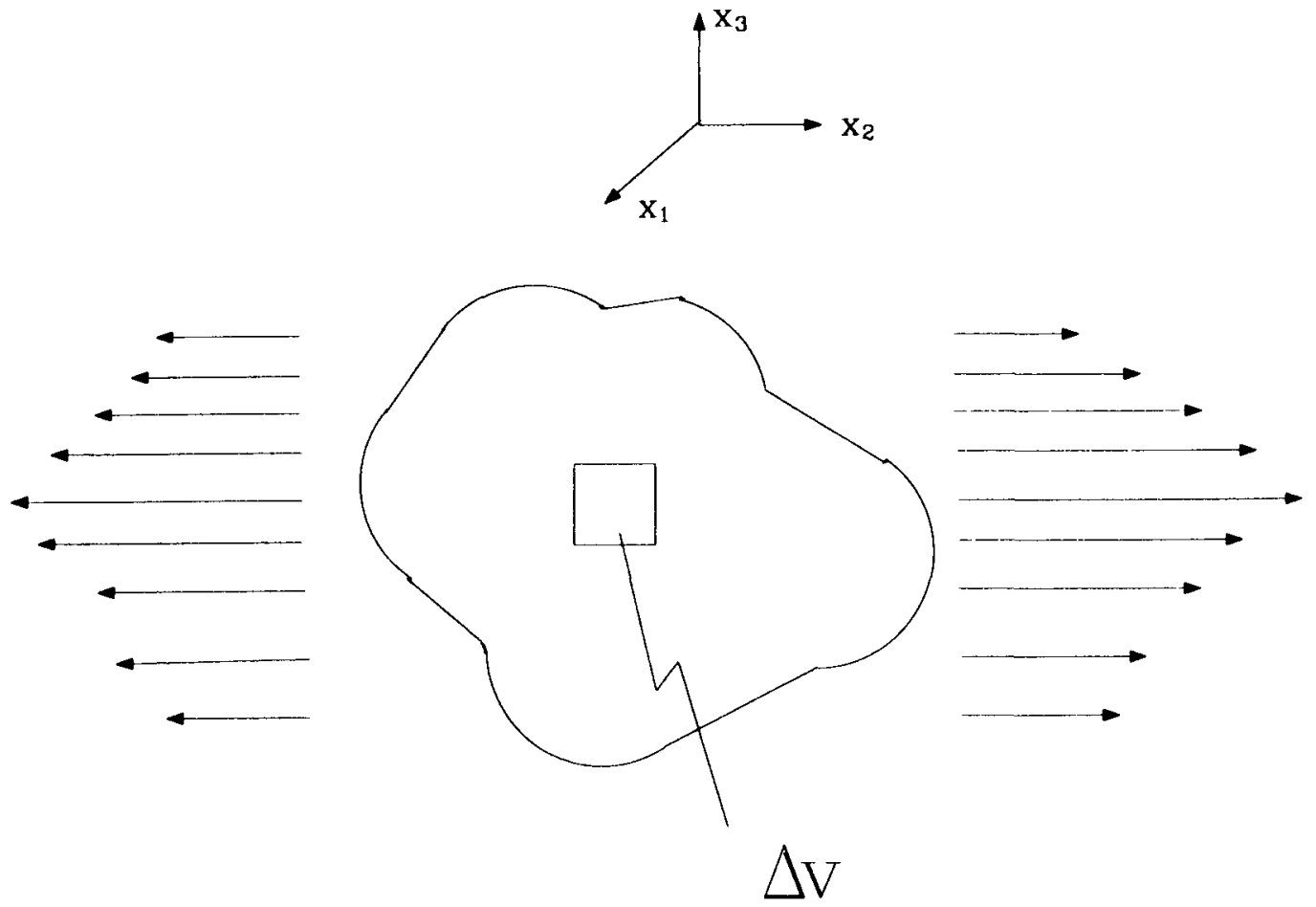

Fig. 1. Stress that varies but remains uniaxial.

$$
\mathrm{P}_{\mathrm{s}}^{\text {total }}=\mathrm{P}_{\mathrm{s}}^{\Delta \mathrm{v}_{1}} \cdot \mathrm{P}_{\mathrm{s}}^{\Delta \mathrm{v}_{2}} \cdot \mathrm{P}_{\mathrm{s}}^{\Delta \mathrm{v}_{3}} \ldots \cdot \mathrm{P}_{\mathrm{s}}^{\Delta \mathrm{v}_{\mathrm{M}}}
$$

where

$$
P_{s}^{\Delta v_{i}}=\exp \left\{-\left[\left(\frac{1}{m} !\right)\left(\frac{\sigma\left(x_{i}\right)-\sigma_{u}}{\bar{\sigma}_{u v t}-\sigma_{u}}\right)\right]^{m}\right\}
$$

Again, taking the natural log of Eq. (6) and multiplying and dividing each term by $\Delta \mathrm{v}_{\mathrm{i}}$, we get

$$
\ln P_{s}^{\text {total }}=\frac{1}{\Delta v_{i}} \sum_{i=1}^{N}-\left[\left(\frac{1}{m} !\right)\left(\frac{\sigma\left(x_{i}\right)-\sigma_{u}}{\bar{\sigma}_{u v t}-\sigma_{u}}\right]^{m} \Delta v_{i}\right.
$$

We now require $\Delta v_{i}$ to be unity in size, while the measure of unity approaches zero as $\mathrm{N}$ approaches $\infty$. In the limit, we have

$$
\ln P_{s}^{\text {total }}=\frac{1}{\eta} \int_{v}-\left[\left(\frac{1}{m} !\right)\left(\frac{\sigma\left(x_{i}\right)-\sigma_{u}}{\bar{\sigma}_{u v f}-\sigma_{u}}\right)\right]^{m} d v ;
$$


here, we have made $\Delta v_{i}=\eta$ one unit of volumes, that is, $\mid \boldsymbol{m}=1$ unit of volume, and, again, we maintain the symbol for dimensional homogeneity. Thus, for a nonuniform stress field, where the stress varies

in magnitude but not in direction,

$$
P_{s}^{\text {total }}=\exp \left\{\frac{1}{\eta} \int_{v}-\left[\left(\frac{1}{m} !\right)\left(\frac{\sigma(x)-\sigma_{u}}{\bar{\sigma}_{u v t}-\sigma_{u}}\right)\right]^{m} d v\right\}
$$

\section{PRINCIPLE OF INDEPENDENT ACTION (PIA) AND MULTIAXIAL STRESS FIELDS}

Equation 8 is the most fundamental basis for the Weibull model we implemented. Following the approach discussed in Ref. 12, we postulate that the contribution to the survival probability of the material at a particular point is the sum of the effect of the principal stresses there. Such an element of volume is shown in Fig. 2, with $\sigma(j)$ being the state of the principal stress field. For a nonuniform stress field and for the volume $V_{i}$,

$$
P_{s}^{V_{i}}=\exp \left\{-\frac{1}{\eta} \sum_{j=1}^{3} \int_{v}-\left[\left(\frac{1}{m} !\right)\left(\frac{\sigma(j)-\sigma_{u}}{\sigma_{u v f}-\sigma_{u}}\right)\right]^{m} d v\right\}
$$

where $\eta=1$ unit volume.

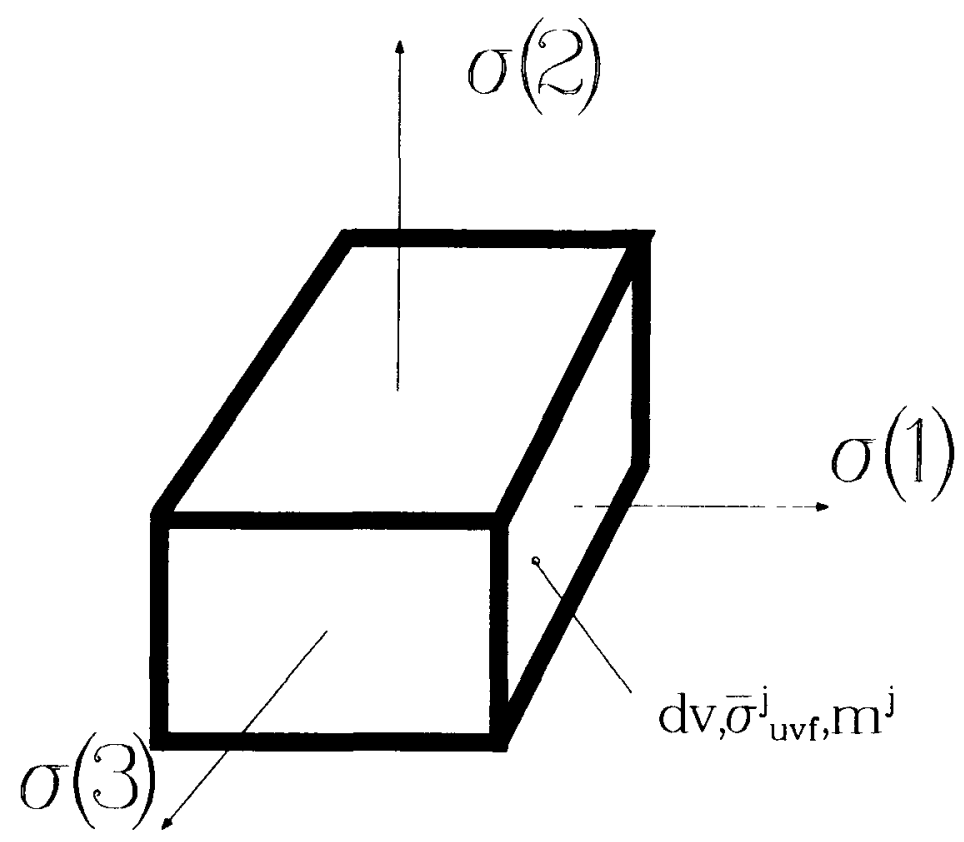

Fig. 2. Principal stresses acting on a differential volume element $d v$. 
The fundamental PIA assumption is that only a Mode I crack or flaw contributes to fast fracture.

As pointed out in Ref. 13, there should be no problem in principle, in incorporating any failure criteria that is desired into Eq. (8). Several other failure criteria have been proposed and are in general use, but nearly all of them are based on some stress invariant or on a combination of stress invariants. One such failure criteria is based on the Mises-Huber-Heneky criteria, ${ }^{20}$ which basically says that failure occurs when the critical magnitude of equivalent stress $\sigma_{e}$ is reached, where

$$
2 \sigma_{\Theta}^{2}=[\sigma(1)-\sigma(2)]^{2}+[\sigma(2)-\sigma(3)]^{2}+[\sigma(3)-\sigma(1)]^{2} .
$$

Incorporating this criterion into a Weibull model is an application of Eq. (8).

\section{Anisotropic Materials}

For materials whose strength properties vary in direction, we must modify the model represented by Eq. (8). Appropriately, the model that will be implemented into our ABAQUS installation will reduce to the isotropic model if all directional properties are the same. ${ }^{12,13}$

Let the set of orthogonal material axes $\lambda_{1}, \lambda_{2}$, and $\lambda_{3}$ represent the principal material directions such that the strength of the material in these directions can be plotted on them. We assume that $\lambda_{1}$ is the strongest direction, and that

$$
\bar{\sigma}_{\mathrm{uvf}}^{(1)}>\bar{\sigma}_{\mathrm{uvf}}^{(2)}>\bar{\sigma}_{\mathrm{uvf}}^{(3)}
$$

but this is not a programming restriction.

Failure data for materials tested uniaxially in directions other than the principal material directions generally tend to fall on a triaxial ellipsoidal surface, with semi-major axes given by the values of the mean unit volume strengths in the $\lambda_{i}$ space (see Fig. 3.) The equation of this surface is

$$
\left(\frac{\lambda_{1}}{\bar{\sigma}_{\mathrm{uvf}}^{(1)}}\right)^{2}+\left(\frac{\lambda_{2}}{\frac{\sigma_{\mathrm{uvf}}^{(2)}}{\sigma^{2}}}\right)^{2}+\left(\frac{\lambda_{3}}{\bar{\sigma}_{\mathrm{uvf}}^{(3)}}\right)^{2}=1 .
$$




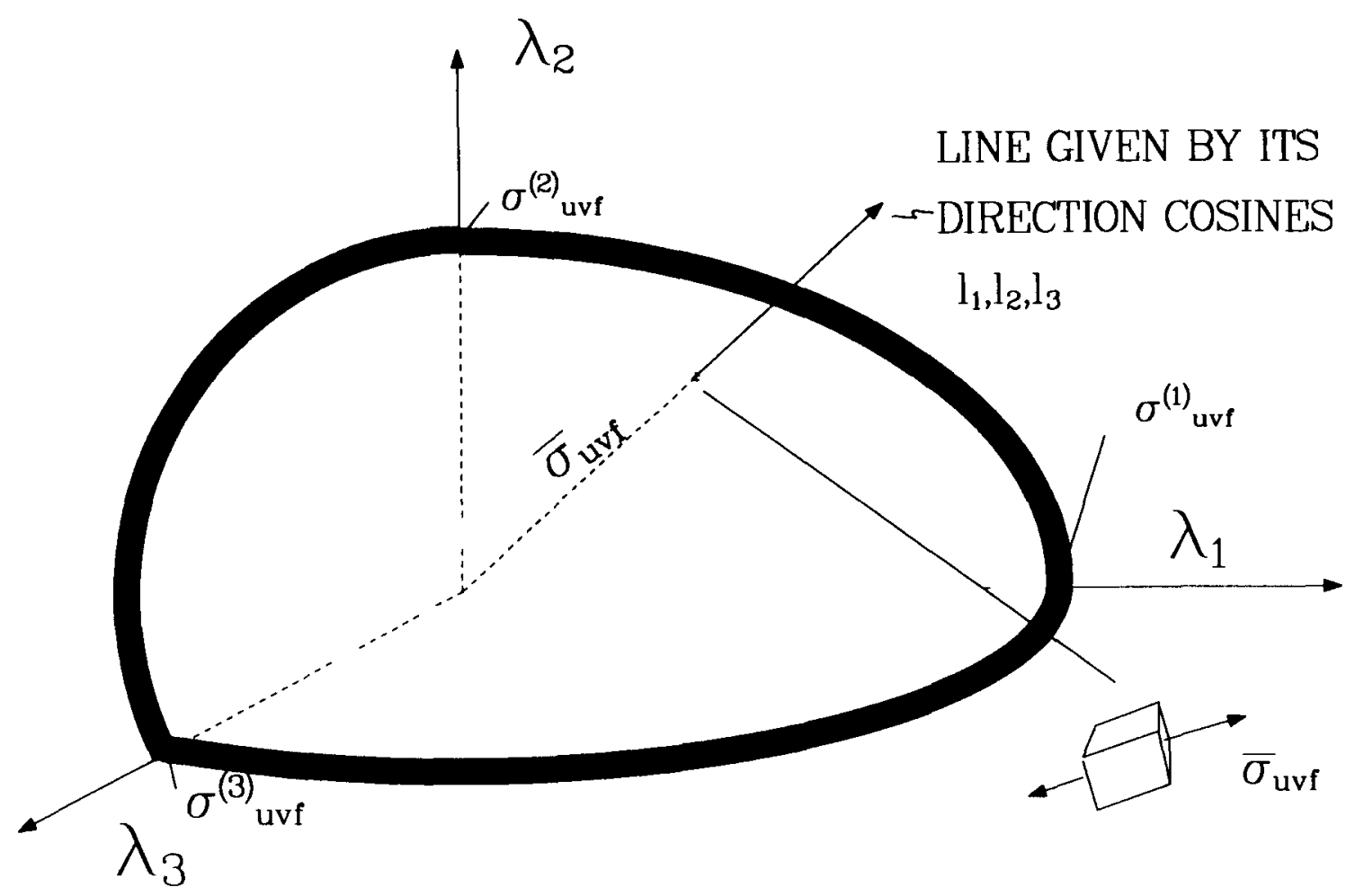

Fig. 3. The failure surfaces in $\lambda_{1}$ space.

The $\bar{\sigma}_{\text {uvt }}$ point on the ellipsoid represents the failure in a uniaxial state of stress in the direction associated with the line whose direction cosines are $l_{1}(i=1,3)$ in the $\lambda_{1}$ space. The equations of this line are

$$
\frac{\lambda_{1}}{l_{1}}=\frac{\lambda_{2}}{l_{2}}=\frac{\lambda_{3}}{l_{3}}=\bar{\sigma}_{\text {uvt }} \text {, }
$$

or alternatively, the $\bar{\sigma}_{\text {uvf }}$ point on the failure surface has the coordinates

$$
\lambda_{1}^{\circ}, \lambda_{2}^{\circ}, \lambda_{3}^{\circ} \text {, given by } \lambda_{1}^{\circ}=\bar{\sigma}_{\text {uvf }} \text {. }
$$

Clearly, then, the mean unit volume failure stress $\bar{\sigma}_{\text {uvf }}$, under a state of uniaxial stress in the direction given by the direction cosines $I_{1}$, is found by solving Eqs. (11) and (12) simultaneously, which gives

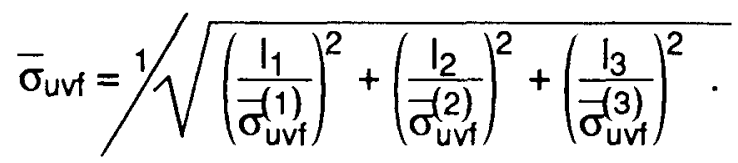


Note that, at present, this equation restricts the global axes to alignment with the material axes because $I_{i}$ are in the global system. We suppose that our anisotropic material also has the following Weibull directional properties:

$\mathrm{mi}=$ the Weibull modulus in the $\mathrm{j}$ direction,

$\sigma_{\mathrm{uvf}}^{j}=$ the mean unit volume strength in the $\mathrm{j}$ direction, and

$\sigma_{u}^{j} \quad=$ the threshold stress assiciated with the $\mathrm{j}$ direction.

A generalized Weibull model, based on the principal of independent action and Eq. (9), is

$$
P_{s}^{V_{i}}=\exp \left\{-\frac{1}{\eta} \sum_{j=1}^{3} \int_{v}\left[\left(\frac{1}{m^{j}} !\right)\left(\frac{\alpha j)-\sigma_{u}^{j}}{\overline{\sigma u v f}_{\mathrm{u}}-\sigma_{u}^{j}}\right]^{m j} d v\right\}\right.
$$

All directional properties are determined from Eq. (13) or a similar one with $\mathrm{m}$ or $\sigma_{u}$, as needed, replaces $\bar{\sigma}_{\text {uvf }}$ and the direction cosines $l_{i}$ are the direction cosines associated with the principal stress $\sigma(j)$ at any point in the volume.

Actually, the Weibull modulus, experimentally, is nearly independent of direction for most materials, but the data sets we have seen are seldom large enough to agree on a single value. Keeping the modulus in this form allows the analyst considerable flexibilty and keeps the analyst from having to choose a modulus or use an average value or some other method. In addition, if a material has known directional dependent Weibull moduli because of processing or fiber orientation, then the model will still apply.

This anisotropic model given by Eqs. 13 (generalized) and (14) will reduce to all other PIA models found in the literature. This is the model we implemented into our ABAQUS installation.

\section{Finite Element Implementation}

Equations 13 (generalized) and 14 have been implemented on an element-byelement basis, so the volume involved is the individual finite element volume, and the survival probability of the element is calculated. Thus, the total probability of failure of the structure is given by

$$
P_{f}^{\text {total }}=1-\prod_{i=1}^{N} P_{s}^{i}
$$

where $\mathrm{N}$ is the total number of elements, and 
$\prod_{i=1}^{N}$ has the usual meaning of the product taken over $N$ elements of each $P_{s}^{i}$, implying independent $P_{s}^{i}$ and a weakest link hypothesis.

In the finite element calculational flow for a displacement formulation, stress recovery is made at each element integration point following the displacement calculation. This point in the solution is by far the best place to implement the POF calculation (Eq. 14) because only the weighted element differential volume (which is available at this point) and a summation scheme are needed for implementation. Many of the reported finite element POF calculations in the literature use a postprocessing scheme, but we have chosen to include the calculation as part of the finite element process because of the ease of implementing it at this point in the calculational flow.

There are several possibilities for including the POF calculation in the ABAQUS program. These possibilities include adding a completely new element. Thought, however, convinced this author that the best approach was through a "UMAT" user subroutine. ABAQUS allows various user subroutines to be included in the solution process. Subroutine UMAT is called at each element integration point and expects the Jacobian matrix of the constitutive model $\partial \Delta \tilde{\sigma} / \partial \Delta \tilde{\varepsilon}$ to be returned and the stress tensor to be updated. For elastic materials that follow Hooke's Law, $\tilde{\sigma}=C \tilde{\varepsilon}$, and the Jacobian matrix is just $C$. This matrix is well known and well documented for isotropic and anisotropic finite elements. 21,22 We will assume the reader has a working knowledge of the finite element process for an incremental program like ABAQUS, and we will not describe this part further. Subroutine UMAT is entered for each element and at each element integration point for stress recovery during an increment. Thus, Eq. 14 is integrated numerically over the finite element i by

$$
P_{s}^{i}=\exp \left\{-\frac{1}{\eta} \sum_{j=1}^{3} \sum_{n=1}^{G}\left[\left(\frac{1}{m^{j}} !\right)\left(\frac{\sigma(j)-\sigma_{u}^{j}}{\sigma_{u v f}-\sigma_{u}^{j}}\right]^{m j} D V_{n}\right\}\right.
$$

where $\mathrm{DV}_{\mathrm{n}}$ is the weighted differential volume at the integration point and $\mathrm{G}$ is the total number of integration points. $\mathrm{DV}_{\mathrm{n}}$ and other needed variables exist in FORTRAN common blocks in the ABAQUS code and are obtained in this manner. For the details of the integration process, the reader is referred to any modern finite element text, such as Ref. 22. A flow-chart summarizes subroutine UMAT in Fig. 4. Subroutines to obtain principal stresses and directions are callable from UMAT, and the relevant procedure is described in the ABAQUS users manual. ${ }^{17}$ 


\section{SUBROUTINE UMAT}

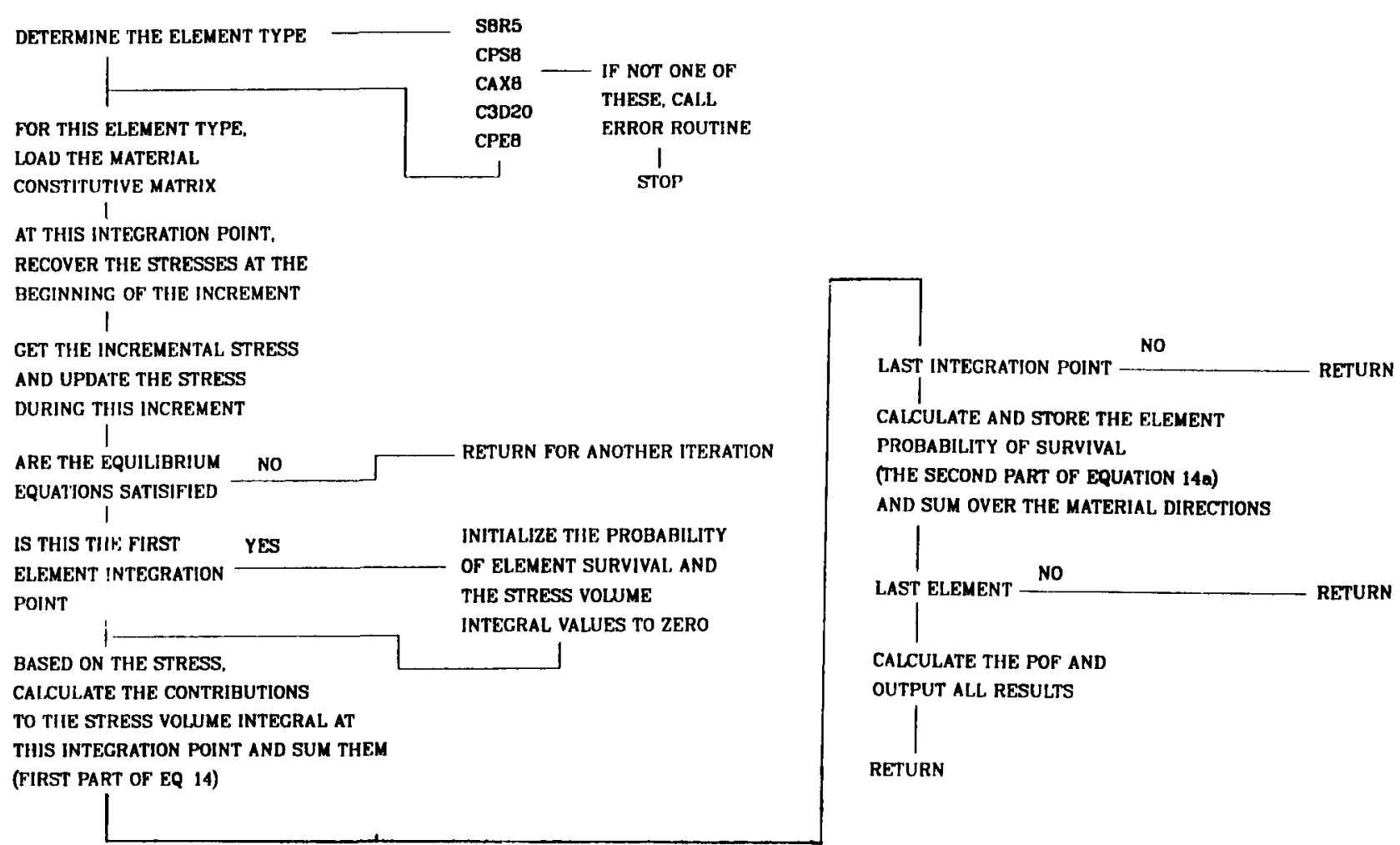

Fig. 4. Flow chart for the ABAQUS subroutine UMAT.

\section{A FURTHER DISCUSSION OF THE MEAN UNIT VOLUME STRENGTH}

The passage from experimental volume-dependent data to the mean unit volume strength is a concept needed for predicting the POF of a structure under a nonuniform state of stress. In fact, the mean unit volume strength and the Weibull moduli are the parameters that, presumably, are constant in magnitude for a given material (thus, material properties) though we assume directional dependence. Often these are not the tabulated parameters; however, we perceive that the problem is the lack of a universally accepted method for treating the Weibull statistical failure model under a multiaxial state of stress. Probably, the same statement can be made about failure theories in general, with the real test being how well they do in a predictive mode. However, there seems to be a feeling that ductile materials are in better shape. The following is quoted from Ref. 16. 
"In principle, the failure test should be conducted with a stress state the same as that predicted in the prototype structure. In the case of ductile metals, however, a long history of careful experimentation has shown, as will be discussed in Unit 6, that correlation between failure in simple stress states to that in complicated states can be made through failure theories. This is not yet the case with brittle materials and therefore failure predictions based upon simple tests for complex situations are necessarily suspect. However, because of its simplicity in operation and the attractive economics of specimen preparation, the 3 and 4 point beam bending, or modulus of rupture (MOR) test, has become almost a standard failure test technique and the results therefrom employed in developing statistical models for complex states. These models must be employed with caution for any but those states approximating the simple beam stress state until experimental evidence, which is now being accumulated in attempts to establish this correlation, is carefully studied."

Although this quote is from a 1979 reference, the author has seen nothing in the literature that would invalidate it. Thus, as will be illustrated, in the absence of a universally agreed upon model for multiaxial stress states, we have adopted the one developed here for our ABAQUS installation.

In any case, the relationship shown in Eq. (5) is for data from uniaxial tensile specimens. As stated in the quote, much of the test data for these brittle materials comes from a 3 or 4 point bending test used to define a parameter called the modulus of rupture (MOR). The MOR is the failure stress determined from the famous flexure formula, $\sigma=\mathrm{Mc} / \mathrm{l}$. For this type of data, the assumptions given in the analysis leading to Eq. (5) do not hold, and another relationship between the mean unit volume strength $\bar{\sigma}_{\text {uvf }}$ and $\bar{\sigma}^{\text {mor }}$, the then reported modulus of rupture, must be found.

Figure 5 shows a MOR test specimen. The procedure for determining the Weibull material properties would be to take all the data from testing a number of these specimens and use it to develop the following Weibull expression:

$$
P_{f}=1-P_{s}=1-\exp \left\{-\left(\frac{\sigma^{m o r}-\sigma_{u}}{\sigma_{f}^{\text {mor }}-\sigma_{u}}\right)^{m}\right\}
$$

$$
\begin{aligned}
\text { where } \sigma^{\text {mor }} & =\text { the modulus of rupture, determined by } \\
\sigma_{\text {mor }} & =6 \mathrm{M}_{\text {rupture }} / \mathrm{bh}^{2} \\
\bar{\sigma}_{\mathrm{for}} & =\text { the mean value of the MOR, and } \\
\mathrm{M}_{\text {rupture }} & =\text { the maximum applied moment at rupture. }
\end{aligned}
$$




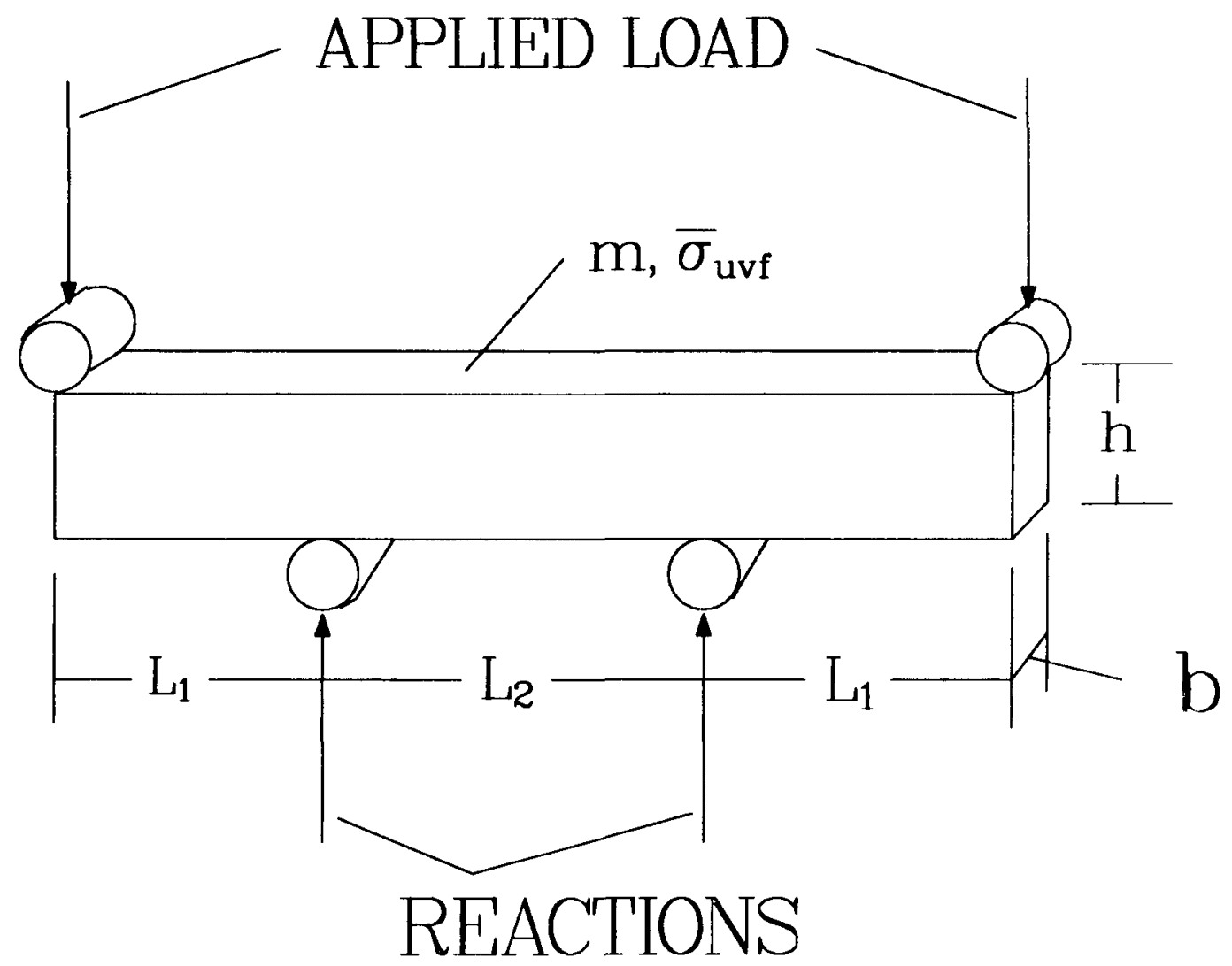

Fig. 5. The MOR test specimen configuration corresponding to Eq. 16.

To develop the relationship for $\bar{\sigma}_{\text {uvf }}$ from these tests, the expression for the stress at any point in the beam in terms of the bending moment is substituted into Eq. (8) with $s_{u}=0$ for integration over the beam volume. However, the further assumption is made that only the tensile stress will contribute to $\bar{\sigma}^{\text {mor }}$, so the integration is carried out only over the upper half of the beam. The resulting expression for the log of the survival probability is

$$
\ln P_{s}=\frac{1}{\eta}\left(\frac{1}{m} !\right)^{m} \frac{6^{m}}{b^{m-1} h^{2 m-1}}\left(\frac{M_{0}}{\bar{\sigma}_{u v f}}\right)^{m}\left(\frac{2 L_{1}+(m+1) L_{2}}{2(m+1)^{2}}\right)
$$

where $M_{0}$ is the maximum value of the bending moment. The log of the expression from the test data with $\sigma_{u}=0$, Eq. (15), will be

$$
\ln P_{s}=-\left(\frac{\frac{6 M_{0}}{b h^{2}}}{\bar{\sigma}_{f}^{\text {mor }}}\right)^{m}
$$


Equating Eqs. (16 and 17) will result in

$$
\bar{\sigma}_{\mathrm{uvf}}=\left(\frac{\mathrm{V}+\mathrm{mbhL_{2 }}}{2 \eta(m+1)^{2}}\right)^{1 / m}\left(\frac{1}{m} !\right) \bar{\sigma}_{\mathrm{for}}^{\text {mor }} .
$$

Presumably the $\bar{\sigma}_{\text {urf }}$ value from a set of tensile test data and from a set of MOR test data will agree if this quantity is truly a material property.

The author has occasionally seen torsional test data in the literature. ${ }^{9}$ We record for completeness the following expressions. For a solid torsional (circular cross section) specimen

$$
\bar{\sigma}_{\text {uvf }}=\left(\frac{2 V}{\eta(m+2)}\right)^{1 / m}\left(\frac{1}{m} !\right) \bar{\tau}_{f},
$$

where $\bar{\tau}_{f}$ is the mean value of the fracture shear stress computed from

$$
\tau=\frac{T R_{0}}{J},
$$

with $T=$ the torsional moment at fracture,

$R_{0}=$ the specimen outer radius, and

$\mathrm{J}=$ the polar moment of inertia.

Similarly, for a hollow torsional specimen,

$$
\bar{\sigma}_{\text {uvf }}=\left\{\frac{2 \pi L}{\eta \cdot R_{o}^{m}}\left(\frac{R_{o}^{m+2}-R_{1}^{m+2}}{m+2}\right)\right\}^{1 / m}\left(\frac{1}{m} !\right) \bar{\tau}_{f},
$$

with $R_{i}$ being the inner radius and $L$ the torsional specimen length.

\section{THE STATS COMPANION SYSTEM}

At Los Alamos there is an interactive version of a program called STATS (Ref. 23), for determining the Weibull parameters from a set of test data. This program performs a linear least square fit to the data via an analysis in the following form: Let

$$
\begin{aligned}
& \sigma_{u}=0, \\
& P_{f}=1-\exp \left[-\left(\frac{\sigma}{\sigma_{f}}\right)^{m}\right],
\end{aligned}
$$




$$
\begin{aligned}
& 1-P_{f}=\exp \left[-\left(\frac{\sigma}{\sigma_{f}}\right)^{m}\right], \\
& \frac{1}{1-P_{f}}=\frac{1}{\exp \left[-\left(\frac{\sigma}{\sigma_{f}}\right)^{m}\right]} \\
& \ln \left(\frac{1}{1-P_{f}}\right)=\left(\frac{\sigma}{\sigma_{f}}\right)^{m}, \text { and } \\
& \ln \left[\ln \left(\frac{1}{1-P_{f}}\right)\right]=m \ln \sigma-m \ln \bar{\sigma}_{f},
\end{aligned}
$$

which is of the required form of $y=m x+B . P_{f}$ (the expected value) is calculated by ranking the total number of $\mathrm{N}$ data points in increasing order, then

$$
P_{f}=\frac{i}{N+1}
$$

where $\mathrm{i}=$ the rank of a given point $\sigma$. When $\mathrm{P}_{\mathrm{f}}$ and the corresponding point $\sigma$ are known, a linear least square fit can be performed on the data by putting it into the form of Eq. (21). Then the $m$ and $\bar{\sigma}_{f}$ are determined as the slope and from the intercept.

An illustration of the use of STATS and its output for Fort St. Vrain graphite can be had from the data in Ref. (11). Table 3.2 in that reference gives the with-grain and against-grain failure data from tensile test specimen found in Ref. (9). Some of the plotted output of STATS for the with-grain data are shown in Fig. 6. This output gives $\mathrm{m}=16.566$ with $\bar{\sigma}_{f}=3702$. When we apply Eq. (5) to the specimen used in the test $\left(V=0.0494\right.$ in. $\left.{ }^{3}\right)$, we then have $\sigma_{\text {ovf }}^{\mathrm{wg}}=3102 \mathrm{psi}$ for the with-grain data. Similarly, the against-grain data from Ref. 9 show that $m=14.573, \bar{\sigma}=3092$, and $\overline{\sigma u v f}=2480$ psi.

STATS plots the linear curve fit for Eq. (21), the cumulative distribution function, Eq. (1), and the probability distribution function (its derivative), and shows the data points so that an "eye" discernable estimate of the goodness of fit can be made.

\section{EXAMPLE PROBLEMS}

In this section, examples are presented that will illustrate the use of the Weibull model to predict the POF of various finite element representations of structures. These examples were selected primarily for verifiying the model. 


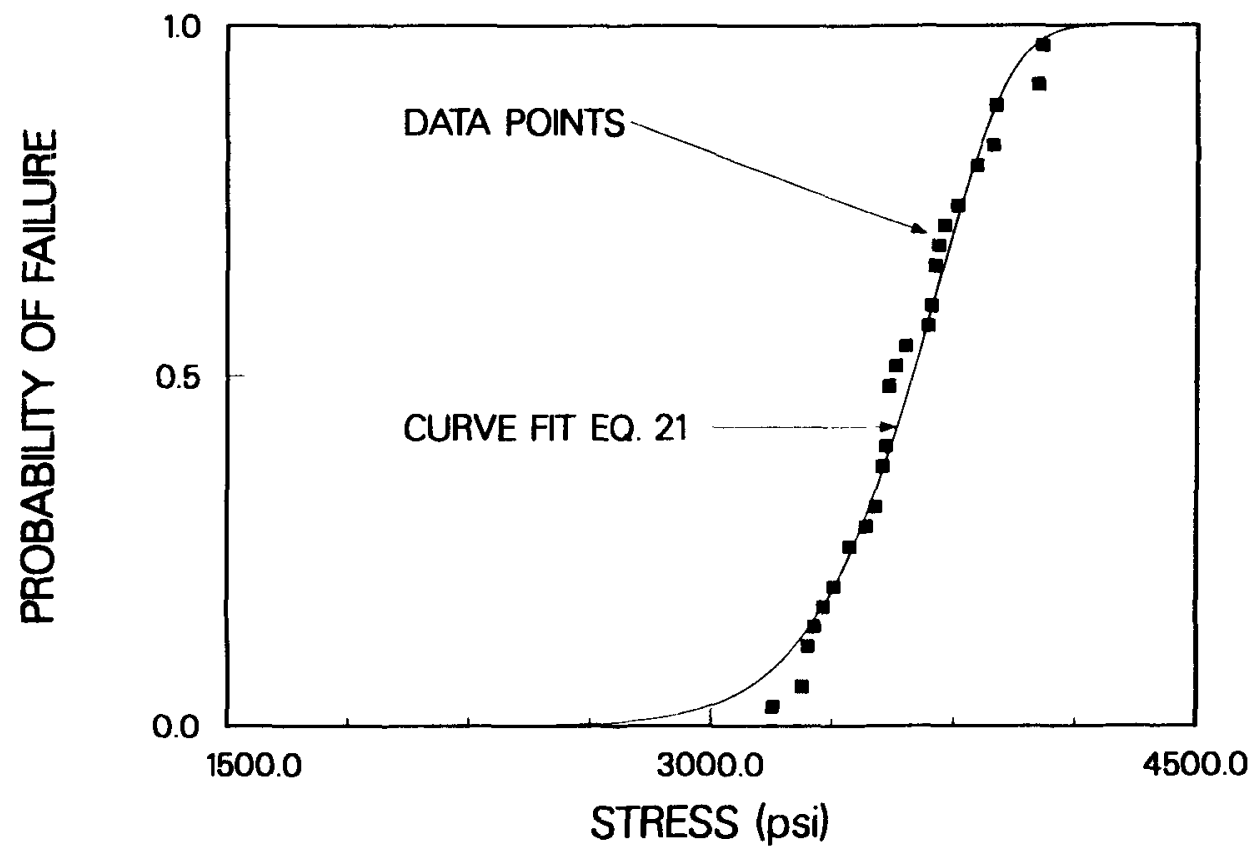

Fig. 6. The Weibull cumulative distribution function and properties $\bar{\sigma}_{f}$ and $\mathrm{m}$, determined from Ref. 9, for the with-grain experiments on graphite tensile specimens. The curve is the Weibull fit, with the data points shown as squares.

\section{Example 1 - Pressurized Ring}

The example chosen here is also used in Ref. 13. In this example, a thick wall ceramic ring is under internal pressure. The exact solution for the stress field for this example is known to be (Ref. 24), where

$$
\begin{aligned}
& \sigma_{\theta}=\frac{P_{i} R_{l}^{2}}{R_{0}^{2}-R_{l}^{2}}\left\{1+\left(\frac{R_{o}}{r}\right)^{2}\right\}, \\
& \sigma_{r}=\frac{P_{i} R_{1}^{2}}{R_{o}^{2}-R_{i}^{2}}\left\{1-\left(\frac{R_{o}}{r}\right)^{2}\right\}, \text { and } \\
& \sigma_{z}=0
\end{aligned}
$$

and where,

$\mathrm{P}_{\mathrm{i}}$ = internal pressure,

$R_{i} \quad$ inner radius of the ring,

$\mathrm{R}_{0}=$ outer radius of the ring,

$r=$ radial coordinate,

$\sigma_{\mathrm{r}}=$ radial stress, and

$\sigma_{\theta}=$ hoop stress. 
Because the exact stress field is known everywhere, because the stresses are also the principal stresses, and because of their form, the integrals involved in the evaluation of the POF can be carried out exactly using the binominal expansion theorem. For example, the hoop stress is the maximum principal stress $s(1)$; thus,

$$
\begin{aligned}
& S(1)=\int_{V}\left(\frac{\sigma_{\theta}}{\bar{\sigma}_{u v f}}\right)^{m} d v, \text { so } \\
& S(1)=\left(\frac{P_{i} R_{i}^{2}}{R_{0}^{2}-R_{i}^{2}}\right)^{m}\left(\frac{1}{\bar{\sigma}_{u v i}}\right)^{m} \int_{V}\left\{1+\left(\frac{R_{0}}{r}\right)^{2}\right\}^{m} r d r d \theta d z .
\end{aligned}
$$

Using the binominal expansion theorem,

$$
\begin{aligned}
S(1)= & 2 \pi h\left(\frac{P_{i} R_{i}^{2}}{\overline{\sigma_{u v f}\left(R_{0}^{2}-R_{i}^{2}\right)}}\right)^{m} \int_{R_{i}}^{R_{0}}\left\{1+m\left(\frac{R_{0}}{r}\right)^{2}+\frac{m(m-1)}{2 \cdot 1}\left(\frac{R_{0}}{r}\right)^{4}\right. \\
& \left.+\frac{m(m-1)(m-2)}{3 \cdot 2 \cdot 1}\left(\frac{R_{0}}{r}\right)^{6}+\cdots+\left(\frac{R_{0}}{r}\right)^{2 m}\right\} r d v .
\end{aligned}
$$

The other principal stress $S(2)=\sigma_{r}$ can be handled similarily; $S(3)=\sigma_{z}$ is zero for plane stress. Thus, the POF may be determined exactly. Table I shows the parameters chosen to evaluate the code's ability to model this ring.

TABLE I

$R_{i}$ (in.)

$R_{0}$ (in.)

I (height (in.))

$\mathrm{m}$ (Weibull modulus)

$\bar{\sigma}_{\text {uvf }}$ (unit volume strength lb/in.2)

2

THICK WALL CYLINDER ANALYSIS

Ratio of compressive to tensive strength

3

0.25

15

262.8

8 
We used an axisymmetric finite element mesh for this model, and, as shown in Fig. 7, we calculated the POF exactly, using ABAQUS for the chosen ring at various pressures. There is no visible difference between the finite element POF prediction and the exact POF prediction for this problem.

\section{Example 2 - A Silicon Nitride Disc, Spin-Tested To Failure}

The data for this example is taken from Ref. 14. In this example, we compare the implementation of the theoretical model we have described with several other models that try to extend the concept using fracture mechanics (Fig. 8). Although the other models are interesting, from a theoretical point of view, the nature of the statistics of brittle materials and the assumptions that are required to implement these models on a continuum mechanics level appear to be neither justified nor productive. Table II shows the parameters used in making the computation for Fig. 8.

\section{Example 3 - A Graphite Ring Experiment Under External Mechanical Load and a Thermal Gradient}

Reference 11 describes an experimental program that investigated Fort St. Vrain reactor grade graphite under combined thermal and mechanical loadings. In that program, we did material tests on both tension and torsion specimens, to determine the material properties, and on several combined thermal-mechanical loadings (to failure) on ring specimens. We use this reference to fully illustrate the combined usage of the

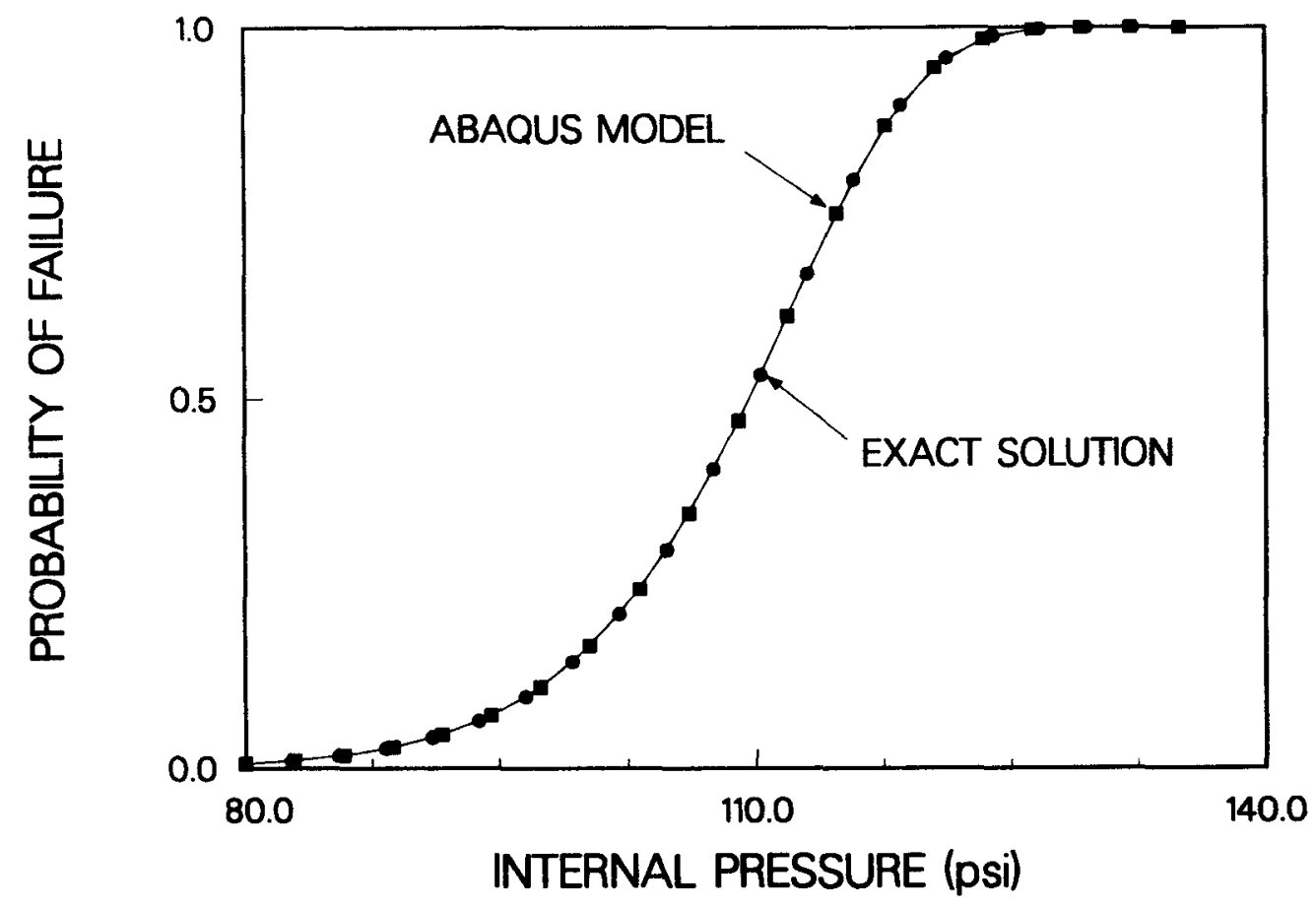

Fig. 7. A comparison of the ABAQUS POF model vs the exact solution for the POF of a thick ring under internal pressure. 


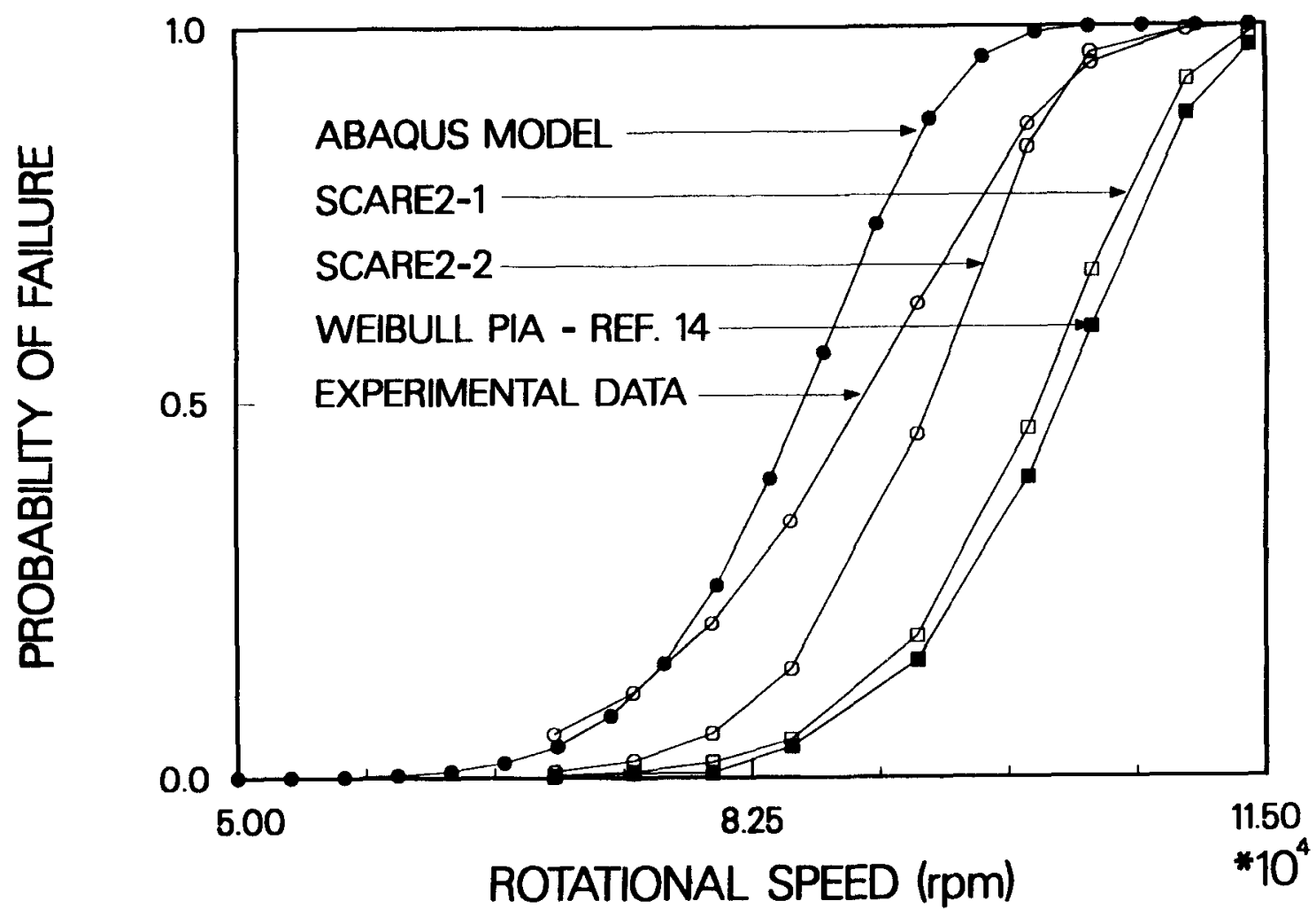

Fig. 8. Various Weibull models compared with the experimental data from Ref. 7.

TABLE ॥

THE PARAMETERS USED FOR THE CALCULATIONS SHOWN IN FIG. 8

Disk outside radius $R_{0}$

Disk inside radius $R_{\mathbf{i}}$

Thickness $\mathrm{t}$

Unit volume strength $\bar{\sigma}_{\mathrm{uvf}}$

Weibull modulus $\mathrm{m}$

Young's modulus $E$ of elasticity

Poisson's ratio $n$

Disk spin speeds
$=41.275 \mathrm{~mm}$

$=6.35 \mathrm{~mm}$

$=3.80 \mathrm{~mm}$

$=827 \mathrm{MPa}$

$=7.65$

$=300 \mathrm{GPa}$

$=0.11$

$=50-115 \mathrm{kRPM}$

STATS program and the ABAQUS Weibull model. The STATS analysis of the data from Ref. 11, as reported (in the section entitled "The STATS Companion System" in this work), gave the parameters shown in Table III for the Weibull properties in the againstgrain and with-grain directions. With the other properties taken from Ref. 11, the plane stress mesh shown Fig. 9 was used to model the room temperature experiments carried out in Ref. 11. 
TABLE III

PARAMETERS USED IN CALCULATIONS FOR EXAMPLE 3

Inside radius $R_{i}$

Outside radius $R_{0}$

With-grain Young's modulus $E_{1}=E_{3}$

Across-grain Young's modulus $E_{2}$

In-plane shear modulus $G_{12}=G_{13}$

Out-of-plane shear modulus $\mathrm{G}_{23}$

Ratio of compressive to tensile strength

With-grain unit volume strength

Against-grain unit volume strength

With-grain Weibull modulus

Against-grain Weibull modulus

Weibull volume symmetry factor
$=3$ in.

$=8$ in.

$=1.37 \times 10^{6} \mathrm{psi}$

$=1.12 \times 10^{6} \mathrm{psi}$

$=0.71 \times 10^{6} \mathrm{psi}$

$=2.27 \times 10^{6} \mathrm{psi}$

$=2.7$

$=3102 \mathrm{psi}$

$=2480 \mathrm{psi}$

$=16.567$

$=14.573$

$=4$

\section{DIRECTION OF MAXIMUM \\ MAXIMUM STRENGTH}
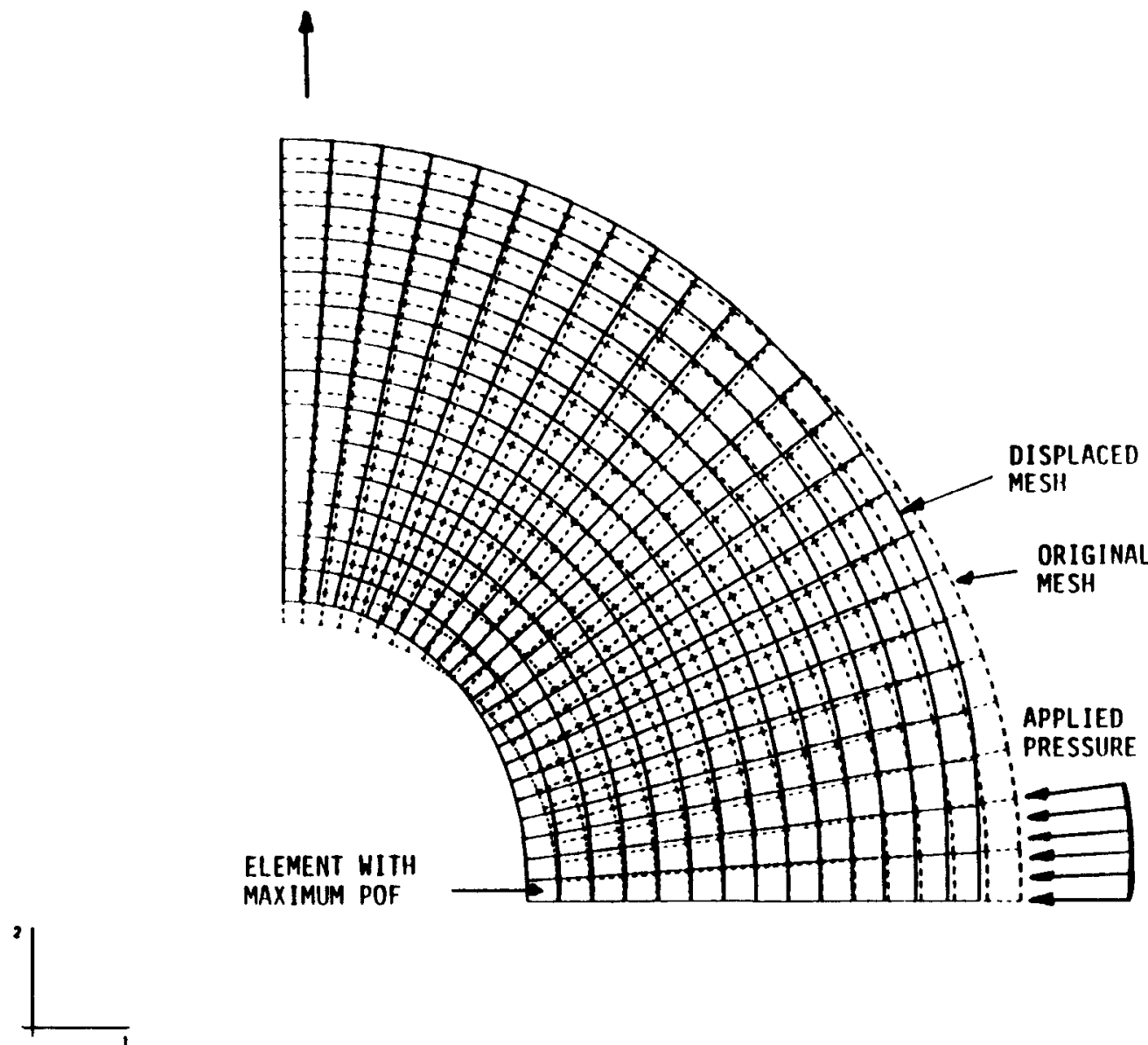

Fig. 9. Quarter-symmetry plane-stress mesh for example 3. 
The results of the against-grain-loading ABAQUS prediction and the band of experimental results are shown in Fig. 10. The code overpredicts the experimental mean failure load by about $7 \%$, but for the experimental "database" of 4 points, this overprediction is not very serious. Of more interest is that, for this problem, the POF prediction for the ring is dominated entirely by the single element indicated in Fig. 9. Examination of the fracture patterns in Fig. 6.1 of Ref. 11 show clearly the accuracy of this approach for indicating the location of fracture initiation.

The input data deck for this example is given in Fig. 11 with line-by-line descriptions. Note the use of a Weibull volume symmetry factor of 4 . The POF is volume-dependent and the total amount of "stressed material" must be accounted for in Eq. 14. Because we have modeled only one-forth of the volume by using symmetry, the differential volume used in the integration of Eq. 14 must be multiplied by 4 . The output of the code gives the Weibull volume, which should agree with the total volume of stressed structure (that is, not the volume modeled, but 4 times the volume modeled).

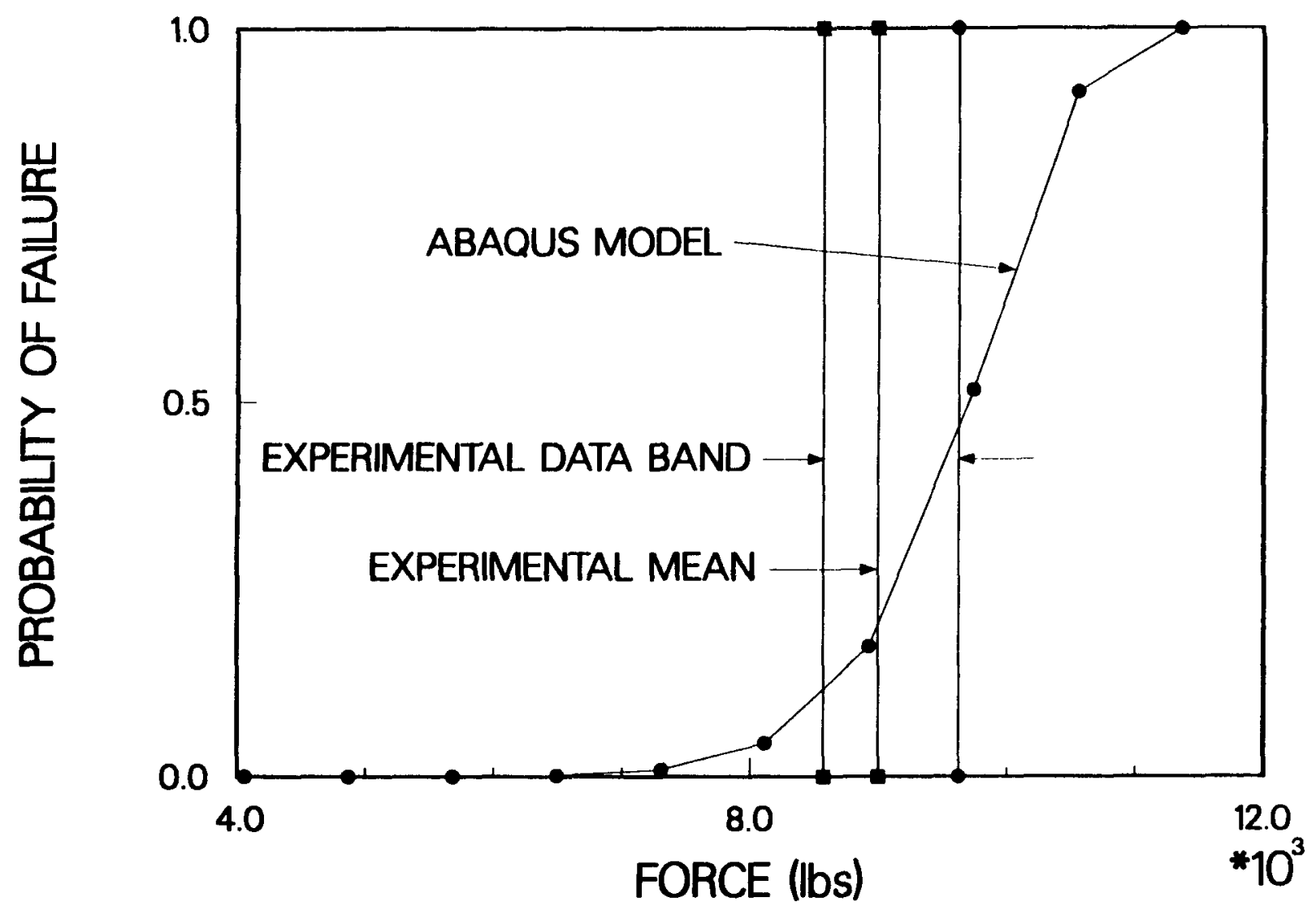

Fig. 10. The POF prediction by ABAQUS for the loaded graphite ring, from Ref. 11 , with the 4-point experimental data band and the mean shown for comparison. 


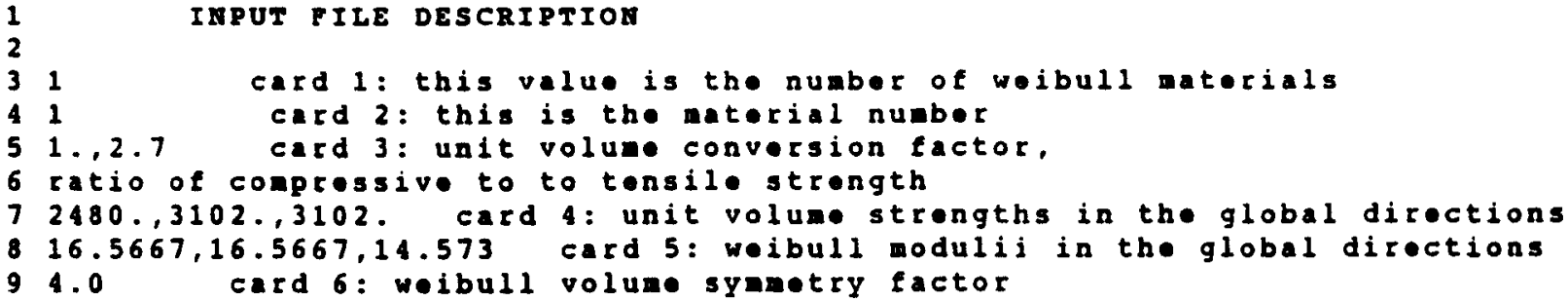

Fig. 11. A sample input file for UMAT with the lines annotated.

\section{Example 4 - An MHTGR Fuel Block Under Normal Operation}

This example is used to illustrate the thermoelastic capability of the model and to further emphasize the Weibull volume symmetry factor. Figure 12 shows a finite element mesh and boundary conditions for a symmetry segment of an MHTGR fuel block of the type proposed for use in the NPR program. This mesh represents a socalled unit cell of the fuel block. The properties shown in Table IV were used for this example to compute the Weibull probability of fracture of a fuel block under normal operating conditions. Note the Weibull volume symmetry factor of 3600 . The stress field for this example is solely caused by the thermal conditions imposed on the model and predicts a POF of $1 \times 10^{-8}$, a quite reasonable value.

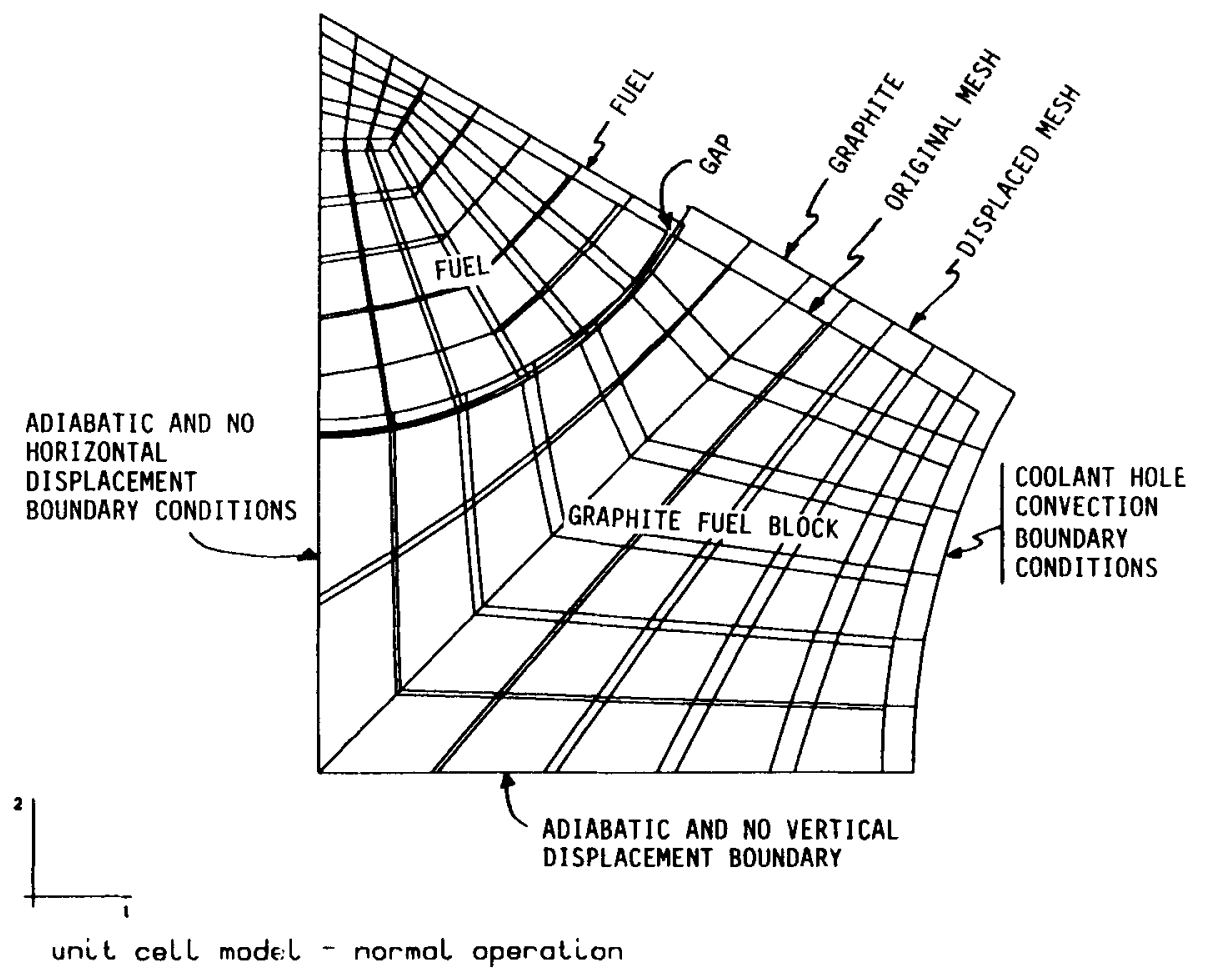

Fig. 12. The finite element mesh for example problem 4. The fuel is a heat- 
TABLE IV

PARAMETERS USED FOR THE CALCULATIONS OF EXAMPLE 4

Young's modulus of elasticity

Poisson's ratio

$=8.5 \times 10^{9} \mathrm{~N} / \mathrm{mm}^{2}$

Thermal conductivity max. $134 \mathrm{~W} / \mathrm{m}^{\circ} \mathrm{C}$ at $295^{\circ} \mathrm{C}$

$=0.1$

$\min .32 .4 \mathrm{~W} / \mathrm{m}^{\circ} \mathrm{C}$ at $3000^{\circ} \mathrm{C}$

Coefficient of thermal expansion $-6.1 \times 10^{-6}$ per ${ }^{\circ} \mathrm{C}$

Unit volume strength $-2.13 \times 10^{7} \mathrm{~N} / \mathrm{mm}^{2}$

Weibull modulus - 14.575

Weibull volume symmetry factor $=3600$

\section{CONCLUSIONS}

A Weibull POF model was implemented through a user subroutine for the ABAQUS program. It is available for the elements shown in Fig. 4. (This subroutine can easily be made available for other orders of integration of these elements.) The model has been tested on some problems with known solutions or with an experimental database, and has been demonstrated to be accurate at predicting the POF for materials with known Weibull properties.

This model and its associated program STATS, when applied by an experienced analyst, should prove useful both in design applications and in safety analysis for brittle materials.

The advantage of attributing the status of a material property to $\bar{\sigma}_{\text {uvf }}$ are obvious. This assumption could, and should, be thoroughly checked by adequate databases using different types of material testing specimens and different sizes of models. We are unaware of the status of any papers, pro or con, in this area, except for the material cited in Ref 16. Instead, it appears that more activity and time has been spent in incorporating fracture mechanics models into an already at-best statistically dominated continuum approximation. Perhaps this approach should be reevaluated. 


\section{REFERENCES}

1. W. Weibull, "A Statistical Theory of the Strength of Materials," in Proceedings of the Royal Swedish Institute for Engineering Research, No. 151 (1953).

2. W. Weibull, "A Statistical Distribution Function of Wide Applicability," Journal of Applied Mechanics, pp. 293-97 (September 1951).

3. T. T. Shih, "An Evaluation of the Probabilistic Approach to Brittle Design," Engineering Fracture Mechanics. 13, 2, 257-271 (1980).

4. S. B. Batdorf, "Some Approximate Treatments of Fracture Statistics for Polyaxial Tension," International Journal Fracture, 13, 1, 5-11 (February 1977).

5. S. B. Batdorf and J. G. Crose, "A Statistical Theory for the Fracture of Brittle Structures Subjected to Nonuniform Polyaxial Stresses," ASME Journal of Applied Mechanics 41, 2, 459-466 (June 1974).

6. G. Alpa, "On a Statistical Approach to Brittle Rupture for Multiaxial States of Stress," Engineering Fracture Mechanics, 19, 5, 881-901 (1984).

7. L. R. Swank and R. M. Williams, "Correlation of Static Strengths and Speeds of Rotational Failure of Structural Ceramics," Ceramic Bulletin, 60, 8, 830-834 (1981).

8. J. D. Buch, J. G. Crose, and E. Y. Robinson, "Failure Criteria in Graphite Program," Air Force Materials Laboratory report, AFML-TR-77-16, Final Report (March 1977).

9. M. A. Sherman, "Mechanical Property Evaluations of H440 Fine-Grained Graphite," Southern Research Institute report, SORI-EAS-84-146, Final Report (February 1984).

10. F. Ho and E. Chin, "Test Evaluation Report of the Thermal Stress Test for Core Support Graphite," General Atomic report 904445A (August 1980).

11. C. A. Anderson, G. W. Fly, L. B. Lundberg, and J. A. Romero, "An Investigation of H440 Graphite When Subjected to Combined Primary and Secondary Stress," Los Alamos National Laboratory report NUREG/CR-3965 LA-10652-MS (April 1986), pp. 26-32.

12. P. Stanley, H. Fessler, and D. V. Sivill, "An Engineer's Approach to the Prediction of Failure Probability of Brittle Components," in Proceedings of British Ceramic Society, 22, 453-487 (1973). 
13. J. Margetson, "Failure Probability Evaluation of an Anisotropic Brittle Structure Derived from a Thermal Stress Solution," in Proceedings of International Conference on Thermal Stresses in Materials and Structures in Severe Thermal Environments (Plenum Press, New York, 1980) 503-519.

14. J. P. Gyekfenyesi, "SCARE: A Postprocessor Program to MSC/NASTRAN for Reliability Analysis or Structural Ceramic Components," Transactions of the ASME, Journal of Engineering for Gas Turbines and Power, 108, 540-546 (July 1986).

15. W. H. Dukes, "Handbook of Brittle Material Design Technology," North Atlantic Treaty Organization Advisory Group for Aerospace Research and Development (December 1990).

16. J. I. Mueller, A. S. Kobayashi, and W. D. Scott, eds., "Design with Brittle Materials," University of Washington, College of Engineering report, Seattle, Washington (1979).

17. Hibbitt, Karlsson, and Sorensen, Inc., "ABAQUS User's Manual," Version 4.6 (1987).

18. S. P. Girrens and J. G. Bennett, "An Infinite Element for the ABAQUS Finite Element Code," Los Alamos National Laboratory report LA-11363-MS (November 1988).

19. F. B. Hildebrand, Advanced Calculus for Applications (Prentice-Hall, Inc., Englewood Cliffs, New Jersey 1964).

20. S. H. Crandall and N. C. Dahl, eds., An Introduction to the Mechanics of Solids (McGraw-Hill, Inc. New York,1959), 195-228.

21. O. C. Zienkiewicz, The Finite Element Method. 3rd ed. (McGraw-Hill, London, 1977).

22. O. C. Zienkiewicz and R. L. Taylor, The Finite Element Method, 4th ed. (McGrawHill, London, 1989).

23. W. D. Scott, "STATS," University of Washington Computer Program, Version 2/25978 Ceramic Engineering, Seattle, Washington.

24. S. Timoshenko and J. N. Goodier, Theory of Elasticity (the Maple Press Company, York, Pennsylvania, 1951). 